\title{
Restorative Parenting: Delivering Trauma-Informed Residential Care for Children in Care
}

\author{
S. L. Parry ${ }^{1}$ (D) $\cdot$ T. Williams $^{1} \cdot$ C. Burbidge ${ }^{1}$
}

Accepted: 10 March 2021 / Published online: 24 March 2021

(c) The Author(s) 2021

\begin{abstract}
Background There are 78,150 children in care in England and 12\% live in group residential settings. Little empirical research informs our understanding of how these vulnerable children heal from multi-type trauma in residential homes. Evidence-based multisystemic trauma-informed models of care are needed for good quality consistent care.

Objective Using a novel multisystemic trauma-informed model of care with an embedded developmental monitoring index, the Restorative Parenting Recovery Programme, pilot data was collected from young people and care staff from four residential homes over a two-year period. Five key developmental areas of children's recovery were investigated through monthly monitoring data. Staff were also interviewed to explore their experiences of delivering the intervention to contextualise the findings.

Methods Data was gathered from 26 children, aged 6-14 years, over a two-year period. Their developmental wellbeing was measured using the Restorative Parenting Recovery Index and analysed through a comparison of means. To add further context to this preliminary analysis, qualitative interviews were undertaken with 12 Therapeutic Parents to explore their perceptions of how the Restorative Parenting Recovery Programme influenced the children's development.

Results Young people showed significant improvements on indices relating to relationships $(p=0.002, d=0.844)$. Significant changes are observed during the first half of the programme in self-perception $(p=0.006, d=0.871)$ and self-care $(p=0.018, d=0.484)$, although limited progress around self-awareness and management of impulses and emotions.
\end{abstract}

Conclusions This novel integrative approach to re-parenting and embedded measurement system to track the children's progress is the first of its kind and has originated from extensive multisystemic clinical practice.

Keywords Looked-after $\cdot$ Residential care $\cdot$ Abuse $\cdot$ Trauma $\cdot$ Attachment

S. L. Parry

s.parry@mmu.ac.uk

1 Manchester Metropolitan University, Manchester, England 


\section{Introduction}

There are currently 78,150 children in care in England (Department for Education, 2019), a $4 \%$ increase from 2018, with $63 \%$ of children entering the care system due to abuse and neglect at home. The National Society for the Prevention of Cruelty to Children's (NSPCC) definition of what it means to be in care is that a child is deemed to be in care if they have been in the care of their local authority for more than $24 \mathrm{~h}$. Of the 9378 children and young people who enter long-term residential care (e.g. secure units, children's homes or semi-independent living accommodation), the percentage of children who have experienced multi-type trauma is even higher. These are arguably the most vulnerable group of young people in care and the system they enter is not currently statutorily regulated, with only a proportion of children's homes regulated and regularly inspected by Ofsted; the Office for Standards in Education, Children's Services and Skills in England. Therefore, vulnerable children and young people who have experienced multiple traumas and relational losses are at risk of further instability and re-traumatisation through a system in need of theoretically robust traumainformed models of care with empirical evidence to support their implementation.

It is comprehensively understood that adversities in childhood can impact global development, particularly in relation to psychological sequelae (Cashmore \& Shackel, 2014; Gilbert et al., 2009; Varese et al., 2012), highlighting "few associations in the mental health literature are as well established as the relationship between child abuse and neglect and adverse psychological consequences among adults" (Horwitz, Widom, McLaughlin, \& White, 2001, p. 184). Further, children in care are overly represented across youth and adult forensic services, homeless populations, and more likely to experience re-victimisation and exploitation if they have not experienced positive and secure relationships during childhood (Brännström et al., 2017). Children in care are five times more likely to be excluded from school compared to their peers (Education, $2018,2019)$ and $39 \%$ of the children in youth forensic centres are looked-after children (Simmonds, 2016). Looked after children are four times more likely to experience a mental health condition and only $14 \%$ achieve $5 \mathrm{~A}^{*}$ - $\mathrm{C}$ grades at age 16 (Bazalgette et al., 2015; Education, 2017).

Overall, outcomes for looked after children are concerning, with education breakdown and involvement with the criminal justice system too common (Berridge, 2008; Halvorsen, 2014; Meltzer et al., 2003; Schofield et al., 2015). Despite the interest in adverse childhood experiences (ACEs) and psychological health in the general population, combined with a recognition that children in care have greater mental health needs than children of the same age in the general population (McCann et al., 1996; Parry \& Weatherhead, 2014), research into the psychosocial impact of being lookedafter is extremely limited (Mullan et al., 2007; Richardson \& Lelliott, 2003). It is however established that looked-after children are amongst the most vulnerable in society (Morrison \& Shepherd, 2015), experiencing many challenges to good mental health (Committee, 2016; Villodas et al., 2016), with problems extending into adulthood for many (Teyhan et al., 2018). This incredibly vulnerable and growing group of young people are disadvantaged across their developmental trajectories, which has an impact upon health, social care and educational systems. Therefore, there is a clear need for effective interventions to help these young people to reduce the impact of childhood hardships in adulthood. 


\section{Trauma-Informed Care for Looked After Children}

Trauma-informed care (TIC) has developed in response to the overwhelming evidence that children in residential care settings have high ACE scores and poor health outcomes (Felitti et al., 1998; Selwyn et al., 2017; Simkiss, Stallard, \& Thorogood, 2013). TIC recognizes the impact of a history of trauma for a person's day-to-day living and the need for traumaaware staff who can provide safe containment and reduce the likelihood of re-traumatization (Cannon et al., 2020). Consequently, many models of residential care share similar underpinnings in relation to attachment frameworks and trauma-informed care (TIC).

Attachment theory is the theoretical framework that can help us understand how and why children are biologically, psychologically and socially driven to form close bonds and connections from birth, usually with one or two main attachment figures, most often parents (Bowlby, 1959). Within TIC models for children's residential care, the attachment figure is often the child's key worker. One-to-one mentorship to nurture hopeful thinking has also been shown to be very effective for children in residential care in Israel (SulimaniAidan et al., 2019). Primary research with young people in residential care in Australia has highlighted that competent and trustworthy carers were essential for a care experience that felt positive and safe (Moorea, McArthurb, Deathc, Tilburyd, \& Roche, 2017). However, where there is often a high attrition of staff and teams working shift patterns, there are many inconsistencies and unpredictabilities that are unavoidable within residential care. Children in care often experience further trauma due to multiple placement breakdowns alongside frequent school, family and peer-group transitions (Haggman-Laitila et al., 2019; Parry \& Weatherhead, 2014), all of which incur further relational instability and losses. Accordingly, by the point children reach a residential setting, it becomes essential to directly target complex trauma through trauma-informed therapeutic care.

Organisations providing TIC need to create a safe space, empower service user involvement and voice, identify trauma-related needs at individual and systemic levels, nurture a culture of wellbeing and resilience for individuals and the organisation as a whole, and work with a 'whole systems' approach, supporting cross-agency collaboration and integrated communication (Dermody et al., 2018; Wilson, Pence, \& Conradi, 2013). Lookedafter children's services can face barriers in terms of delivering TIC due to difficulties in care coordination between an extensive range of health, social care and educational organisations; in addition to attending to the psychosocial needs of the young people and frontline workers, whilst maintaining therapeutic physical environments (Robinson \& Brown, 2016) for both children and staff. Often, competing demands and complex needs outweigh available resources, which can result in suboptimum standards of care.

Therapeutic models and approaches applied to the residential childcare setting usually aim to create a nurturing culture through positive secure relationships and building resilience (Hummer, Dollard, Robst, \& Armstrong, 2010). A number of intervention approaches have been reviewed over recent years (Clarke, 2011; Macdonald, Millen, McCann, Roscoe, \& Ewart-Boyle, 2102), although it is recognised that further practiceoriented research is required (Roberts et al., 2016). Several models of care have been evaluated, including the Model of Attachment Practice, Sanctuary Model, Positive Peer Culture, Dyadic Developmental Psychotherapy, and CARE (Children and Residential Experiences), with many sharing similar attachment based underpinnings (Clarke, 2011; Macdonald et al., 2102; Ribbens McCarthy et al., 2013; Whittaker et al., 2015). The only realist systematic review of inpatient and residential TIC for young people identified 13 studies for inclusion, which had participant numbers of 53-6361 young people (Bryson et al., 2017). 
The five factors that determined the success of implementing TIC across residential and inpatient initiatives were: "senior leadership commitment, sufficient staff support, amplifying the voices of patients and families, aligning policy and programming with trauma informed principles, and using data to help motivate change". It is not currently known which of these factors are also relevant to residential homes for children in care specifically. Further, without standardised outcome measures and agreed means through which to evaluate all models for individual children across services, robust comparisons between the models is presently impossible. Finally, the mechanisms of change that occur through good quality care practices are not well understood, which further complicates the process of measuring positive change.

In summary, the existing empirical literature exploring therapeutic approaches for looked-after children who have experienced multi-type trauma suggests there are many aspects common to all of these established approaches. These comparable aspects are a recognition that children in residential care have experienced multi-type trauma and disadvantage, the belief that staff are required to understand the communicative needs and emotions underlying behaviours, and that staff and children will require support around emotional stabilisation and stress resilience (Macdonald et al., 2102; Ribbens McCarthy et al., 2013; Whittaker et al., 2015).

The current paper presents preliminary findings of emerging data from a novel integrative multisystemic trauma-informed approach to residential care and monitoring data, tracking children's developmental progress across strategic developmental areas. It has been suggested that sharing data may help motivate change (Bryson et al., 2017) and more service level research is required in the field of residential care for looked-after children (Roberts et al., 2016). Further, the novel programme presented with preliminary data offers an incremental contribution to this under-researched area of children's services and the trauma literature in terms of a novel approach to care and measuring progress, within initial insights into how children start to heal from trauma with suitable support.

\section{Introducing the Restorative Parenting Recovery Programme}

The Restorative Parenting Recovery Programme (RPRP; Robinson \& Philpot, 2016) is based upon attachment theory, positive psychology and TIC. Within the RPRP, the child's attachment figure is their key worker, known as the therapeutic parent (TP), recognising the therapeutic aspect of their role within a TIC approach and the importance of stability and consistency for the child. Consequently, practical and therapeutic care for the child is delivered through the TP, with additional supervisory support and monthly team consultations with a member of the clinical team in place to support the TPs. Positive psychology is the study of positive subjective experience in the form of individuality and systemic influences to improve quality of life (Seligman \& Csikszentmihalyi, 2000). The role of positive psychology for TIC models of residential care is emerging, although has potential to significantly lift expectations and aspirations away from pathology and problems towards strengths and successes for staff and children alike. The concept of hope has been defined as the combination of a person's belief in their ability to achieve their goals (their agency) and plan a variety of ways to succeed in the goal (the pathways; Snyder, 1994). Through adopting a positive and solutions focused approach (recently reviewed in Zatloukal et al., 2020), the language can change from being problem focused to solution focused, supporting the child to expand their agency and pathway planning ability. This approach underpins the programme on the assumption that the children have experienced trauma and relational 
loss, and that their thoughts, behaviours and relational styles, to themselves and others, will have been significantly affected by these traumas. Therefore, appreciating the child's actions as communications and clues as to how they may have learned to cope, rather than pathologizing their presentation, the TPs can develop a working formulation as to how the child is coping in the here-and-now, informing their care plan.

With training and support, staff can help a young person develop their self-belief and agency through looking for success instead of failures and positive experiences or accomplishments, however small, instead of negativities. This is the ethos of the RPRP and all staff consultations are undertaken with solutions focused language used to encourage solutions focused thinking. For example, if a TP is feeling stuck or as though they cannot see progress, they are encouraged to think about how they and the child have prevented matters getting worse. If a TP is doubting how progress can be maintained, they are supported to explore their strengths as a practitioner and those of the child to nurture hopefulness.

The RPRP operates on an environmental, sensory, interpersonal, individual and organisational level (Fig. 1). Security and safety are operationalised through therapeutic relationships and careful consideration of the sensory living environment. Monthly consultations with TPs and progress monitoring support engagement with the clinical team and time for safe reflection for frontline staff, essential for reflexive practice (Thomas \& Isobel, 2019). Underpinning this is an education programme from which no child is ever excluded, providing small scale person-centred education that embraces the national curriculum as well as individual needs and TIC in education. The positive impact of trauma-informed residential schools has been evidenced in recent literature as beneficial to wellbeing and learning (Day et al., 2015), although it is recognised further research is required in this area (Berger, 2019).

Collaborative interprofessional working between the clinical, counselling and educational psychology team with TPs, educators and external agencies (e.g. social services, external schools, community groups and healthcare services) supports cohesion in the child's world. Uniquely, the RPRP recognises that as a result of ACEs, the child's regulation systems can be hypersensitive and hyper-responsive, causing difficulties for the child

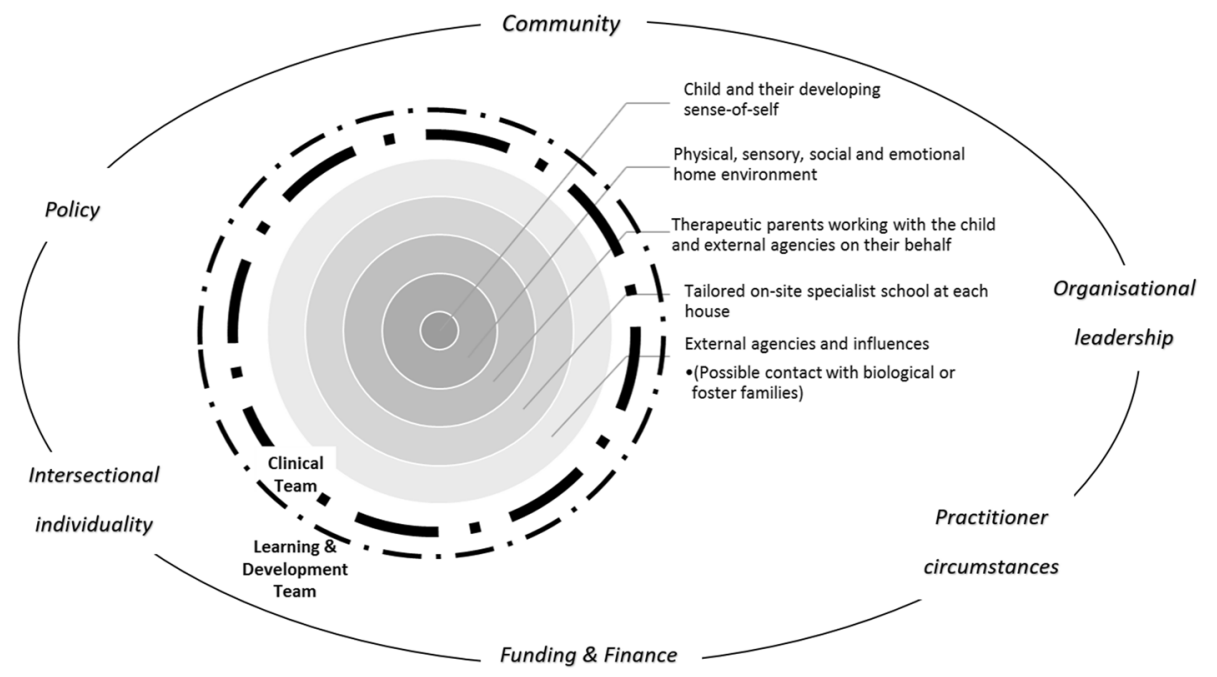

Fig. 1 The multisystemic approach of the RPRP 
in re-calibrating arousal levels to the general environment (Van der Kolk, 2003). Therefore, a central focus of RPRP is to comprehensively provide a tailored low-arousal therapeutic environment, thus reducing the frequency and intensity of a child's stress response to their environment (Shonkoff et al., 2015). The combination of a low-stimulus home environment (e.g. low arousal decoration, soft lighting, soft carpets to reduce noise, avoiding perfumes and unnecessary clutter; (Gaudion, Hall, Myerson, \& Pellicano, 2015; Vogel, 2008) and consistent and accepting interpersonal relationships with TPs are essential to the core healing process. This is prioritised because it is well documented that children who have suffered past trauma can unconsciously revisit sensations associated with that trauma when triggered in the here-and-now by sensory stimuli that were encoded as part of their traumatic experiences (Gaskill \& Perry, 2011). This can therefore cause re-traumatisation at a time when the child has not developed the capacity to deal with these sensations (Furnivall \& Grant, 2014; Van der Kolk, 2003).

All of the children's homes function as a unique family unit and are integrated into the local community to help the children recognise and begin to experience family living. For example, day trips and visits to suitable play areas and centres are arranged and children are encouraged to join local sports groups and clubs when they are socially and emotionally ready to do so. If a child continues to struggle to form relationships with peers, alternatives are explored to help the child develop their confidence and social skills (e.g. activities with art/animals). This process of safely connecting a child to their community through their interests and strengths is a novel and important transitional process within RPRP.

The RPRP encompasses the Restorative Parenting Recovery Index (RPRI; Robinson \& Philpot, 2016) to facilitate the collection of monthly monitoring data to assess the progress children make in five developmental areas: self-care, forming relationships and attachments, self-perception, self-management and self-awareness, and emotional competence. The programme is designed to operate across residential children's homes and the smallscale schools that are integrated into the service. It was hypothesised that the children would quickly benefit from the approach and that there would be some progress in all areas, particularly in terms of positive relationships and self-perception. It was hypothesised that we would see limited development across other measures due to the time it would realistically take to experientially learn, internalise and experience a positive sense of self, which would support psychosocial regulation. In terms of qualitative data collected with staff, all efforts were made not to lead participants in one direction or another, although due to opportunity sampling, we wondered if participants may have a particular interest in TIC and the therapeutic components of training they had engaged in through the programme. This paper presents the theoretical framework for the RPRP and discusses a preliminary analysis of encouraging pilot data from the RPRI.

\section{Method}

\section{Design}

A mixed methods design facilitated the collection and analysis of quantitative data to investigate the progress and development of children and young people along the five index measures of the RPRI. Additionally, a deductive thematic qualitative analysis of data gathered from face-to-face qualitative interviews with TPs added further context and perspective to position this pilot data. 


\section{Participants}

Selected information about the young people within this study is provided to ensure their confidentiality and anonymity. In total, the RPRI data from 20 young people was included in the analysis: 18 males and 2 females with a mean age of 8.9 yrs (range 5-12 yrs; SD 2.174), all of whom were within the two-year RPRP for the duration of the study. Approval for data analysis was gained from Halliwell Homes Ltd. as the service provider for the purposes of service development.

Of the 12 staff members who took part in the qualitative interviews, further details were collected to contextualise their involvement (Table 1). All participants gave written consent prior to participating in the study, which was reviewed and approved through the Research Ethics Committee at Manchester Metropolitan University with the support of Halliwell Homes Ltd. Participants chose their own pseudonym to preserve their anonymity.

\section{Measures and Procedures}

The RPRI (Robinson \& Philpot, 2016) includes the use of five scales, which aim to provide an overall picture of how the young person is healing in a number of key areas following entry to the RPRP. Each of the five scales is measured on a 25-point axis to indicate the general functional level at which the young person is observed to be at by their TP each month. This quantitative data was analysed using SPSS. For the purposes of the qualitative interviews, a Dictaphone and flexible semi-structured interview list of questions and prompts was employed.

The RPRI is used to measure a child's progress on (i) Self-care (SC) (ii) Forming relationships and attachments (FRA) (iii) Self-perception (SP) (iv) Self-management \& selfawareness (SMA) and (v) Emotional competence (EC). Each measure contains five items which are rated using a six-point Likert-type scale (Never, infrequently, sometimes, usually, most often, or always), with responses being coded as 'scores'. The RPRI has been in use across four homes since January 2016. It is completed monthly, considering the child's

Table 1 Demographic data from 12 TPs who took part in qualitative interviews

\begin{tabular}{lll}
\hline & & Count (\%) \\
\hline Gender & Male & $4(33.33)$ \\
& Female & $8(66.67)$ \\
Age (years) & $18-($ up to) 25 & $4(33.33)$ \\
& $25-40$ & $6(50)$ \\
Total number of months & $40-55$ & $2(16.67)$ \\
working in residential care & $0-6$ & $4(33.33)$ \\
& $6-12$ & $1(8.33)$ \\
& $12-18$ & $1(8.33)$ \\
& $18-24$ & $4(33.33)$ \\
in current role & $30-36$ & $1(8.33)$ \\
& $>60$ & $1(8.33)$ \\
& $0-6$ & $4(33.33)$ \\
& $6-12$ & $5(41.67)$ \\
& $12-18$ & $1(8.33)$ \\
& $18-24$ & $2(16.67)$ \\
\hline
\end{tabular}


general behaviour and emotional presentation over the preceding month. To increase reliability of RPRI ratings, the assessment is completed by a TP and assisted by a member of the clinical team. Once the RPRI is completed, total scores against each measure are recorded for every child using only their initials and the date that they entered the programme. This data is stored securely on an internal network for the purpose of assessing and monitoring progress. This study uses the secondary data collected as part of this ongoing assessment process. To maintain anonymity, each initial was converted to a case number before data collection or analysis took place.

Secondary data was available for a total of 71 cases between January 2016 and January 2019. Some of these cases relate to children that are still in the programme, and some who joined before the RPRI was implemented. Consequently, the 20 cases for which a full programme's data was available was aggregated and analysed. For this sample, the average programme duration was 19.9 months (range 6-34 months). Children and young people are usually within the RPRP for 24 months.

Initial assessment of start-to-end time point scores was carried out and an inspection of histograms, boxplots and Kolmogorov-Smirnov tests revealed that the data were normally distributed with no outliers. A paired t-test analysis was therefore conducted to evaluate the impact of the RPRP on scores against each measure (Table 2). In addition to start and end points, three additional time-points for each case were pre-defined to represent quarterway, mid-way, and three-quarter-way points into the programme. For example, case 17's programme duration was 29 months and therefore the 5 time-points were set for this case at months 1, 8, 15, 22 and 29. Where time-points fell between two months, a rounding up system was applied, and the later month was used. For example, case 25 's programme duration was 27 months with a mid-way point clearly set at month 14. However, as the quarter-way point fell at 7.5 months, month 8 was used. Scores against each of the five RPRI measures were taken from each time point for all 20 cases, and a one-way repeated measures ANOVA was conducted to compare scores over time (Tables 2 and 3). An a priori power analysis was not conducted for this study as we were working with the only RPRI data available at the point of analysis. The RPRI is not currently validated and does not therefore have psychometric properties. However, this is the first preliminary analysis of this pilot data, presented to inform future larger-scale longer-term research with this measure.

The pilot results from the RPRI were gathered through routinely collected existing monitoring data with the children and young people's TPs. In order to collect the RPRI data each month, a member of the clinical team visits each of the children's homes to meet with the TPs assigned to each child. Over the course of a semi-structured interview with the clinician, the TPs discuss progress, setbacks and the general wellbeing of the young people they support. This process allows for realistic monitoring of progress and difficulties, and the data is entered into the clinical team records to track progress over time. Importantly, TPs are also requested to submit a progress report each month, which includes a formulation to encourage analytical thinking as to the origins and underpinnings of particular behaviours and communications.

To gather qualitative data from staff, information about qualitative interviews was circulated throughout the organisation by email so that potential participants could contact the third author directly if they wished to participate. Once contact was initiated, participant information sheets were distributed, and an interview was arranged. Prior to the interview, a consent form was read and signed by each participant. The participant was then notified the Dictaphone was going to be turned on and the interview began. The semi-structured questions followed a structured interview guide, broad enough to allow for natural conversation (Wooffitt \& Widdicombe, 2006). The interview was a 'social interaction' based 


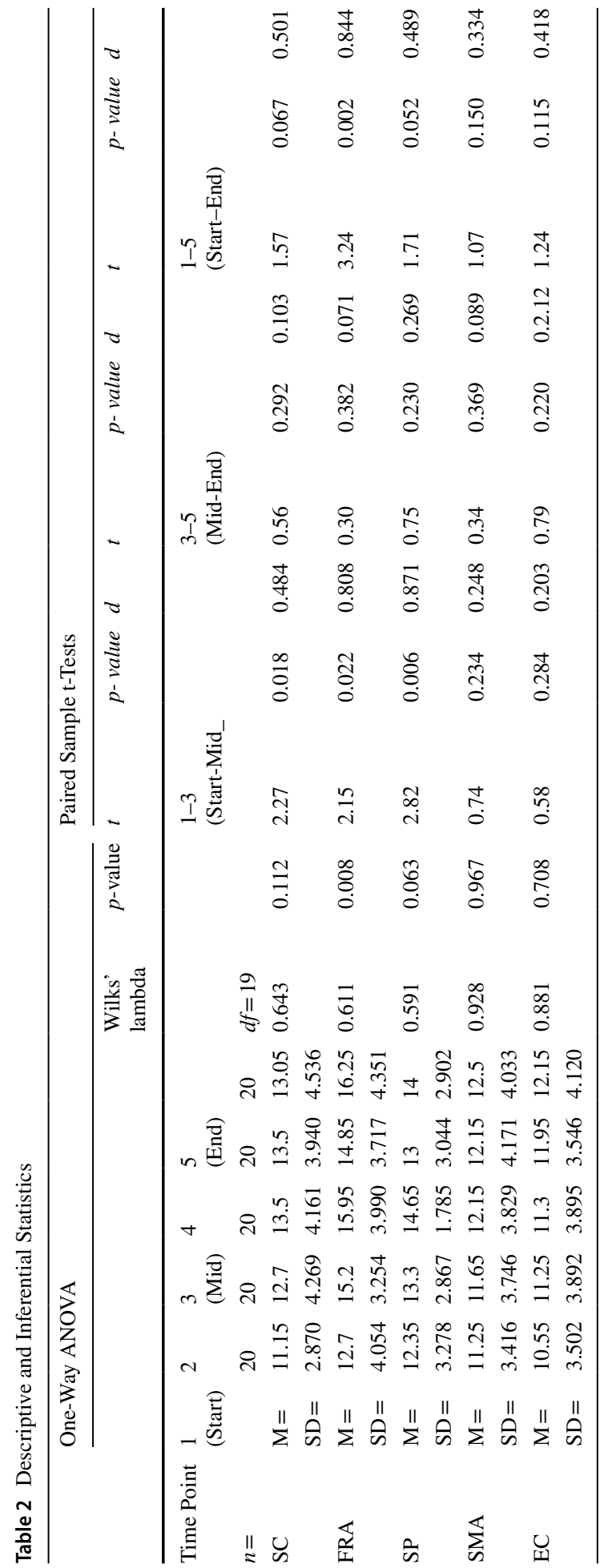


Table 3 Past-hoc Pairwise Comparisons for FRA

\begin{tabular}{lllllc}
\hline $\begin{array}{l}\text { Time point } \\
\text { comparison }\end{array}$ & Mean difference & Std. Error & Adjusted $p$-value & Lower Bound & Upper Bound \\
\hline $1-2$ & -2.500 & 1.139 & 0.408 & -6.115 & 1.115 \\
$1-3$ & -3.150 & 1.147 & 0.447 & -7.802 & 1.502 \\
$1-4$ & -2.150 & 1.195 & 0.879 & -5.942 & 1.642 \\
$1-5$ & -3.550 & 1.097 & 0.043 & -7.030 & -0.70 \\
$2-3$ & -0.650 & 1.210 & 1.00 & -4.491 & 3.191 \\
$2-4$ & 0.350 & 0.809 & 1.00 & -2.217 & 2.917 \\
$2-5$ & --1.050 & 1.200 & 1.00 & -4.858 & 2.758 \\
$3-4$ & 1.00 & 1.156 & 1.00 & -2.670 & 4.670 \\
$3-5$ & -0.400 & 1.315 & 1.00 & -4.572 & 3.772 \\
$4-5$ & -1.400 & 1.106 & 1.00 & -4.910 & 2.110 \\
\hline
\end{tabular}

on perspective, which allowed for open expression, rather than adopted norms (Alvesson, 2003). The interview data was manually transcribed verbatim by the third author, which was initially analysed by the third author through an inductive thematic analysis to capture the breath of the participants' experiences of caring for children in care (Burbidge et al., 2020). The anonymised dataset was then thematically analysed deductively by the first author, specifically in relation to TPs involvement in the RPRP. The second and third authors then reviewed the analysis, provided feedback and questions, which formulated the final analytic themes. Participants were asked eight questions, including: What do you enjoy about your job?; What do you think about the service delivered to the children?; In your opinion, what do you think works well?; Are there any aspects of the service that you think need more attention or improvement?; How do you manage challenges at work?; What support for you as a practitioner would be helpful? The analysis of this data was approved by the Faculty of Health, Psychology, and Social Care Research Ethics Committee within Manchester Metropolitan University.

The six-stage thematic analysis described by (Braun \& Clarke, 2006) was followed, which allowed the researchers to explore participant experiences, motivations and interpretations in relation to the RPRP. However, contrary to inductive methods, the initial coding was undertaken deductively with the anonymised transcripts, informed by the pilot data and research agenda to explore how participants interpreted their experience of being a part of the RPRP. Following familiarisation to reduce researcher interpretation and to preserve linguistic meaning (Madill \& Gough, 2008), the transcripts were annotated, forming initial codes, which involved looking for patterns and common concepts among the data in relation to RPRP. These common concepts formed the basis of a coding framework that the relevant data was then entered in to for further analysis. Once the themes had been reviewed, they were then refined, defined and named (Nowell, Norris, White, \& Moules, 2017). The drafted analysis was then discussed within the team to formulate the final analysis of three themes. Due to the preliminary nature of this pilot study, data saturation and theoretical generalisation were not pursued. However, the qualitative analysis does offer a unique perspective from an under-represented workforce, based on personal accounts of TPs and the Information Power Model of analysis (see Malterud et al., 2016), to provide a novel platform on which to develop further research in this area. The analytic approach facilitated a critical realist conceptualisation of themes within the scope of the 
study (Roth-Yousey et al., 2012) and formed a deductive synthesis of reinterpreted firstperson accounts of the TPs and their systemic experiences of the programme and their relationships with colleagues and the children in their care (Parry et al., 2018).

\section{Results and Findings}

Results from the paired samples t-test show that there was a statistically significant increase in FRA scores from programme start $(M=12.7, S D=4.05)$ to programme end $(M=16.25$, $S D=4.35$ ), $t(19)=3.24, p=0.002$ (one-tailed). The mean increase in FRA scores was 3.55 with a $95 \%$ confidence interval ranging from 5.85 to 1.26. Applying Cohen's $d$ calculations (Cohen, 1988) indicated a large effect size (0.844). Differences in start and end scores against other measures were moderate but not significant (Table 2).

A one-way repeated measures ANOVA was conducted to compare scores against each measure across the five time points, to investigate the effect of time within the programme. The descriptive and inferential statistics for this analysis are also shown in Table 2.

As the ANOVA showed a significant result for FRA scores, a post-hoc analysis (with Bonferroni correction for multiple comparisons) was conducted to see where this difference lies. Pairwise comparisons (Table 3) for FRA shows that differences in scores are only significant between time-point 1 and time-point 5 (start and end) $(p=0.043)$. Figure 2 shows the change in scores at each time point for each measure. Taking into account the small sample size for this preliminary study, we recognise that controlling for type I errors can increase the likelihood of type II errors and result in important effects going unnoticed (Keselman et al., 2004). To further explore where the differences lie across each measure, paired t-tests were conducted for start, middle, and end time points (Table 2). This analysis shows a significant increase in scores within the first half of the programme on 3 out of 5 measures (SC $p=0.018, d=0.484$, FRA $p=0.022 d=0.808$, and SP $p=0.006, \mathrm{~d}=0.871$ ).

While the data from the RPRI show an increase for each measure between the start and end of the Restorative Parenting Programme, this effect is only significant for forming relationships and attachments. Mapping the scores across the five data points shows that FRA and SP scores drop at time-point 4, and SC scores drop at time-point 5. Further investigation of the programme's impact is necessary once a larger sample is available to understand the significance of this trend.

Fig. 2 RPRI Scores across time points

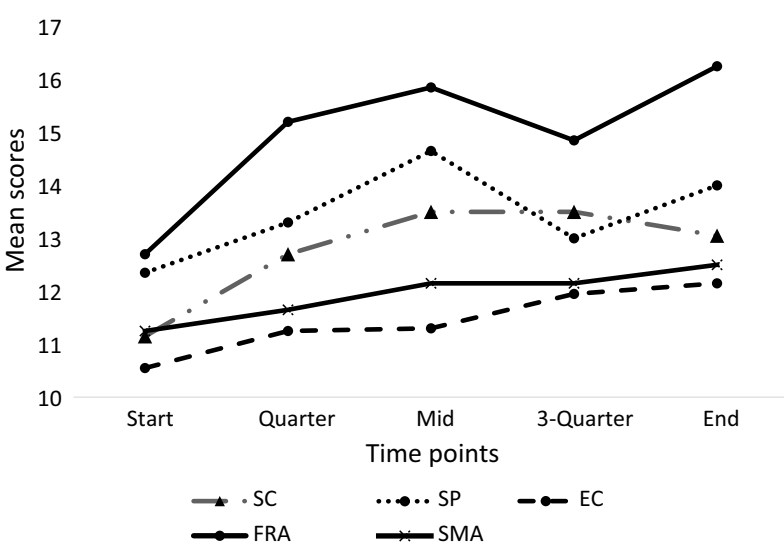


The deductive thematic analysis of the TPs' semi-structured interviews yielded three overarching themes in relation to their experiences of working within the RPRP with the children: (1) Learning and implementing trauma-informed practice and caring, (2), Therapeutic Practices and Relationships, and (3) Reconciling the ethos with the reality. The generation of the themes is illustrated in Fig. 3.

Theme 1. Learning and implementing trauma-informed practice and caring-"I love the kids, I love the staff, I love the programme, I love the training, I love how relaxed it is and I love how the children react" Rose.

Participants reflected that the RPRP was a new way of working and discussed how they had developed greater awareness and therapeutic skills through their training, although also explained how they wanted further specialised training and clinical team support. Importantly, aspects of trauma-aware knowledge and practices were mentioned throughout, for example, "the routine, for them is amazing, they know what they are supposed to be doing every day... it minimises triggers and there's no kind of bargaining with them and challenging them" (Anna); "we just go through the process that we've been trained ... we notice the triggers, the ones that are starting to get a little bit heightened early on and you try and maybe distract them come to something else and change the environment" (Adam). In this way, TPs recognised they were able to take the training and apply it moment-tomoment to support the children. Further, the TPs reflected upon the environmental and relational factors of the provision that they thought were beneficial for healing from trauma: "I think like the environment works well, low stimulus ... the boundaries, the routine... child centred so like putting the children at the forefront and listening to their wishes and feelings... that works well" (Eric). In light of implementing their training, TPs also reflected upon areas for further development in relation to the therapeutic aspects of their role, as Bella describes: "I really do like that therapeutic model ... we're really encouraged

Fig. 3 Thematic Generation

\begin{tabular}{|c|c|}
\hline \multirow{5}{*}{$\begin{array}{l}\text { (1) Learning and } \\
\text { implementing } \\
\text { trauma-informed } \\
\text { practice and } \\
\text { caring }\end{array}$} & Training and therapeutic skills \\
\hline & Know how to notice the triggers \\
\hline & Want more specialised training \\
\hline & Implementing therapeutic practices \\
\hline & Training to boost confidence \\
\hline \multirow{6}{*}{$\begin{array}{l}\text { (2) Therapeutic } \\
\text { Practices and } \\
\text { Relationships }\end{array}$} & The children's voice \\
\hline & The team and professional relationships \\
\hline & Parallel restorative processes \\
\hline & Optimism and hopefulness \\
\hline & Proud parents \\
\hline & Positive choices \\
\hline \multirow{8}{*}{$\begin{array}{l}\text { ( } 3 \text { ) Reconciling } \\
\text { the ethos with the } \\
\text { reality }\end{array}$} & Awareness of needs \\
\hline & Feeling personally responsible for the children \\
\hline & Impact of history in the present \\
\hline & Resource shortfalls \\
\hline & What 'therapeutic' feels like \\
\hline & People and change over time \\
\hline & Prep for the 'second life' \\
\hline & Conflicting systems and processes \\
\hline
\end{tabular}


to do that every day... more guidance on key work sessions... I don't think that we have any training in running those sorts of sessions with kids". Overall, there was a keen desire amongst most TPs to further advance their therapeutic skills and trauma-informed practice.

The workforce spoke positively about training and how trauma-informed training days nurtured their confidence in their work and the programme, although also highlighted how it could become more localised within the homes: "I think we should have more especially within the home for our-specific to our children as well" (Josh). Further, TPs requested training in relation to supporting the children through transitioning out of the programme, recognising this could be a difficult experience for all and possibly reminiscent of previous traumatic losses and transitions: "it would be really useful to have a proper training on preparing kids for the transition out" (Bella). TPs were keenly aware of how the prospect of transitioning out of the programme could be re-traumatising and wished for more support in this area. The quantitative analysis highlights that FRA and SP scores drop at time-point 4, which would typically be when a child's transition to foster care would be in development. This period of uncertainty could influence these areas of wellbeing for the children and heighten anxieties within the workforce as well.

Theme 2: Therapeutic Practices and Relationships- "we give them like hugs and we do treat them like our own children" Jack.

Throughout all the accounts was a focus on the importance of the relationships between the child and TPs, recognising the importance of choice, control and empowerment within TIC:

the rapport between the staff and children, it is really important that they've got somebody there to help de-escalate them really quickly... the children have got a voice as well which is really good, sometimes it's that often that it's forgotten about, but they need their own voice Rose.

TPs also reflected upon the importance of the relationships they had with each other within the system of the service and how these relationships supported their work and each other: "you can see someone starting to get to the point where they are just like I can't do this anymore and you go right I'll swap with you I'm going to stick with this child" (Bella). Communication within the wider team and with primary care professionals was also essential to their role, "we will work as a team to provide the best support for each individual child, but we've got clinical, every other department at head office, doctors, schools, dentists, psychologists - there's a wide range of professionals" (Phil).

An interesting sub-theme that emerged through the accounts was the restorative nature of the work for TPs; a parallel restorative process that developed through positive therapeutic relationships, as Josh explains: "seeing how much they enjoy stuff like that and helping them and that's the most rewarding part about it". The positive psychology aspects of the programme also came through in the form of optimism and hopefulness for the children's futures: "it means you're working with them you've got a goal for them, to see them into a happy family hopefully for the rest of their lives" (Bella). The influence of witnessing positive change, resilience, development and growth appeared to have a profound impact upon the TPs: you just think wow this is really working and seeing that difference and seeing them ... little children who can cope a little bit better, it's just amazing" (Jack). These positive experiences for TPs appeared to further nurture positive elements of the therapeutic relationship:

it's just really rewarding knowing that you've made some sort of difference... the relationships the children have with everyone so like the staff and child relationship is just really, it's a really positive thing most of the time and I think having that they create a positive relationship where they can like talk to you and they feel comfortable with 
you and they feel safe with you to be able to talk to you just gives them that safe space and I think that's the most important thing Jack.

The TPs reflected upon the importance of their relationships with the children as an important mechanism of change. Bella explained, "making connections with the kids and seeing them change and make really good choices and seeing that lasting impact". Reflecting on these changes she witnessed, Bella continued to explain how she contextualised her support, "sometimes it's just basic parenting but you feel you're so proud of them". These insights into witnessing change appeared restorative for TPs as well as providing evidence of a sort that their support and the RPRP were effective for the children, which encouraged the TPs in their work.

Theme 3: Reconciling the ethos with the reality - "the progression they've made and actually seeing them leave and starting a second life all over again" (Phil).

The final theme that emerged through the analysis of the TPs experiences of the programme provides insight into the challenges TPs faced when applying the RPRP in practice. Through their training and experiences with the children in the homes, TPs had developed greater awareness of their needs and the impact of trauma histories upon the children in the present, alongside the dynamic nature of the therapeutic relationship. Whilst professional pride and confidence in the programme appeared to be a restorative factor for many, for example "the therapeutic bit is really important to me and I just think it does really work" (Jack), resource shortages in other areas were problematic.

Due to the changing nature of the homes as children entered and left the programme, some staff teams experienced times of change that led them to reflect upon differences of provision within the same home over time. For instance, one TP reflected upon how it once was and what was now lost in terms of what she perceived to be therapeutic care: "it was perfect because it was, it was therapeutic, we could give each child like one-onone time, like even two-to-one time... to be able to give them that, that time that they need, then the care that they need" (Emma). Just as TPs discussed the reward and joy they felt when they saw children succeeding, they also expressed their sadness when the futures they saw for the children did not materialise, highlighting the authentic emotional connections they developed with the children through the RPRP.

I think the children here are really happy a lot of them don't actually want to leave... the ones [sigh] that it's worked for-it's a two year program here erm so it's not a permanent residential is it... just for children who it hasn't quite worked for might be going into a permanent resi, they don't usually want to go because I think they know it's kind of that's, that's permanent. Anna.

Throughout the accounts was a symbiotic appreciation for the therapeutic and trauma-informed aspects of the RPRP, alongside an unease around how well the RPRP prepared the children for life after the programme, their "second life" (Phil). For instance, differences between the small residential homes and foster family placements were seen as a potential barrier to successful transitions: "you know this isn't anything like a foster placement and I think in terms of a therapeutic residential, it needs to come as close as it can to it and there ain't going to be any foster placement with seven kids, there's really not" (Emma). Mike discussed how little freedom the older children have compared to their peers of the same age and reflected on the impact this may have later on: "I really like the therapeutic home... but then I think sometimes it wraps the children in cotton wool and doesn't give them real insight into what the world is like". Others reflected on particular aspects of the provision that represented a sense of 'home' and 'family': 
I think the fact that we go on holidays works well, like even if it's camping or in a caravan, it just gives the kids a sense of that home environment, just the fact that we do fun things, like it's [residential] not a punishment, it's not their fault Phil.

The unifying focus for all TPs was how the RPRP provided trauma-informed care through relationships for children with histories of trauma and abuse:

they've [the children] had no routine in their life before... their lives have just been chaotic these children, they've had no routine, no boundaries some of them, no they haven't done anything, some of them have been really badly abused and things like that, a routine gives them a focus Lucy.

TPs also reflected upon the children they knew who had progressed to a foster placement and discussed the importance of communication, the child's voice and that they needed to be able to provide an accurate and up to date account of the child's needs to the prospective foster carer. Emma explained: "I do think we should be the first point of contact, we're the ones that know the kids, we work with them every day, day in day out, we know what they love, what they hate...". Overall, there appeared to be some inconsistencies within the workforce in terms of who should ultimately take responsibility for the children's welfare, with some highlighting they knew the children best and others who thought the clinical team should take a leading role. For instance, Eric reflected: "the loss and the grief ... we're only trained so much, we've not got, we're not trained in psychology, we're just trained in like the basics". Within the RPRP (Fig. 1), the TPs are tasked with the re-parenting role and most of the tasks associated with the RPRP are delivered through the Therapeutic Relationship. However, larger structures within the children's system and social care procedures meant that some meetings were held without the child's TP present, reducing their influence over decision making. These instances may go some way to explaining the discrepancies discussed within the staff team as to representing the children and holding parental responsibility. This issue perhaps reflects the time it takes for new structures to become established, especially when they exist within wider organisational structures that have conflicting longstanding processes in place.

\section{Discussion}

Findings from this study provide encouraging results for the implementation of the RPRP as an effective model of care for looked-after children. The preliminary analysis of RPRI data suggests that children make progress against all measures during their time in the trauma-informed programme, with significant results for their quality of relationships, positive self-perception and self-care abilities by the time they leave. Additional analysis of these scores suggests that substantial progress occurs within the first half of the programme, and less significant improvements in outcome scores in the second half. This is reflective of the efforts made to maintain progress while preparing the children for transitioning to foster care. Although limited progress was seen in measures relating to the awareness and management of impulses and emotions, findings from the qualitative study provide some context to these results as TPs reflect on the children's 'chaotic' pasts. Further, the trauma literature emphasises that it can take time for the brain to re-learn mentalisation and impulse control mechanisms, with self-regulation and self-regulated learning appearing interrelated (Panlilio, 2019), which is why emotionally attuned reparenting programmes can be so effective in the longer-term. Positive interactions between children in care and therapeutic carers can enhance the child's sense of self and quality of other 
relationships (Holden, et al., 2010), which is why it is so especially encouraging to see significant improvements around reported quality of relationships and positive self-perception.

Themes emerging from interviews with TPs highlight the incredibly rewarding yet complex nature of implementing a trauma-informed programme of care within a residential setting. TPs reflected on their enthusiasm for the programme, with suggestions that a parallel restorative process develops through therapeutic practices and relationships between children and staff. Professional pride and confidence in the programme's potential for healing was seen to nurture hopefulness and optimism for children's futures. Additionally, learning and implementing trauma-informed practice and care is described as a new way of working that TPs spoke of positively. However, TPs also expressed a desire for further specialised training and support, particularly for children about to transition out of the programme, which seemed to rupture the children's and TPs sense of security within their relationships and thus the safe base they had temporarily managed to create. It would be a recommendation for further programme development to attend to developing a clear attachment-based and TIC plan for managing transitions, for the children and TPs. TPs also demonstrated unease about the children's preparedness for life after RPRP and tried to reconcile the ethos with the reality of resource shortages. TPs reflected on the loss associated with the inevitability of children leaving the home, for which they perhaps need further emotional support to they can remain emotionally attuned to the other children in their home during this period of loss.

Analysis of RPRI data combined with accounts from TPs, point to the therapeutic parent-child relationship as a powerful mechanism of change, supporting the argument that relational trauma requires 'relational repair' (Treisman, 2017, p. 194). This is not surprising, given that many therapeutic models of residential care are underpinned by attachment theory, sharing a focus on building secure and positive relationships (Clarke, 2011; Macdonald, Millen, McCann, Roscoe, \& Ewart-Boyle, 2102). The importance of relationships within the RPRP is also in line with a growing body of research (e.g.Karver et al., 2006; McLeod, 2011; Shirk \& Karver, 2003) suggesting that the therapeutic relationship is more important for psychotherapy outcomes than any specific technique or model. Consequently, the existing literature base supports the need for more attachment-informed endings to the programme, as well as the results of this study.

RPRI scores relating to children's self-perception follow a similar trajectory to those related to relationships and attachments. Changed perception of self and changed interpersonal relationships are cited as measures of posttraumatic growth (Taku et al., 2008). This further demonstrates the importance of relationships within the RPRP and suggests that secure attuned relationships with key attachment figures established after relational trauma can positively inform the child's developing sense of self (Berlin, Cassidy \& Appleyard, 2008). In contrast, the impact of the ecological nature of the homes was less clearly defined and seems an important area for further exploration, particularly from the perspective of young people and how changes in environment influence them before, during and after residential transitions. It would also be interesting to know more about how the architecture of a residential environment and organisational structure dynamically influence therapeutic relationships.

Evident across all TP accounts was the importance of facilitating choice, control and empowerment for children through the relationships. Allowing children's choices and voices to be heard is particularly important for posttraumatic growth, as it addresses the psychological need for autonomy, relatedness and connectedness (Joseph et al., 2012). In addition, TPs' accounts reflected the parallel restorative process that develops as they appear to experience personal growth and fulfilment through their work. Emerging research into trauma work points 
to the potential for vicarious resilience (Henandez, Gangsei \& Engstrom, 2007), as practitioners bear witness to the recovery of those they work with. Vicarious resilience is suggested to counteract fatigue, strengthen practitioners' motivation and facilitate the pursuit of self-care strategies. This is of particular importance for TIC in children's residential care, considering the varying and complex needs of the children in these settings, and the competing demands that staff are often faced with.

Considering these findings, TIC within children's residential homes should be supported by ongoing specialist training for staff. Where possible, training should take place ethnographically within the home and should be delivered to meet the specific needs of children and staff within the unique unit. The relationship between children and staff is incredibly important for healing, and therefore models of TIC should pay special attention to the potential for vicarious trauma and fatigue. The creation of reflective spaces and meaningful reflexive practices should be embedded in TIC to facilitate the self-exploration and personal development of staff, and to promote emotional wellbeing and resilience, which could enhance the practitioner's capacity for emotional attunement with the children. Although optimism and hopefulness were present as codes within the analysis, it was clearly the underpinnings of attachment theory and TIC that were most powerful for catalysing mechanisms of change in the eyes of the TPs.

While findings from the analysis of RPRI data are encouraging, this study only looked at the overall scores for each of the five scales, with a relatively small sample of children who had completed the RPRP. Further in-depth analysis of each individual item is recommended for a larger sample of children over a longer time period. A robust validation study of the RPRI data is also needed to verify the measure for this population. This will enable identification of the areas within each scale that influence the overall scores. For example, the reduction in FRA and SP scores at time-point 5, can be somewhat conceptualised by the TP accounts suggesting that preparing to leave the RPRP has some effect on the child's relationships and self-perception, but further data is needed to understand and address this link. Exploration of children's and education staffs' experiences is also needed to meaningfully investigate the implementation and efficacy of the RPRP and identify the facilitators and barriers for healing within the delivery of the programme. The current study was both helped and limited by the opportunity sample of TPs, which may have meant the sample of TPs who volunteered to take part had a particular interest in TIC. The TP sample was also under-representative of male TPs. Conversely, boys were over-represented in the child sample and future work would benefit from proportional representation across the sample. Larger-scale work could also employ the RPRI in an additional TIC service so that children's progress could be compared with children in the RPRP. The development of a competency framework and RPRP integrity index for practitioner observations could also be beneficial to explore the fidelity with which the RPRP is delivered across the homes. Finally, future research should also collect data from the young people directly at key time points to ensure their perspectives contribute towards the cumulative data. Reflective follow-up meetings with the young people when they approach adulthood would be beneficial to explore the impact of transitions and readjustments.

\section{Conclusion}

The multisystemic trauma-informed approach of the RPRP, and embedded monitoring system of the RPRI, addresses the complexity of childhood trauma through combining a range of theoretical frameworks and adapting these to provide specialist care for children in residential treatment centres. The phasic model of care within the RPRP, which has 
emerged through an existing evidence base for looked-after children and interprofessional service delivery, is a novel and comprehensive approach to supporting looked-after children through the transition into residential care and then foster care that can be extremely unsettling and destabilising for many young people. As the child's lived experience of the approach is paramount in terms of its design and delivery, a phenomenological exploration of the first-person accounts from young people and staff involved in the programme is an essential next step. Further, the formal validation of the RPRI with larger data sets is also required, which would include developing comparative data sets to consider the RPRI against the existing Strengths and Difficulties Questionnaire (Goodman, 1997) and the Winnie Dunn Sensory Profile Assessment (Dunn, 1999). However, the early pilot data and anecdotal evidence from both young people and staff are extremely encouraging, suggesting the RPRP could be a particularly effective model for the trauma-informed care of looked after children. Integrating a range of theoretical frameworks and delivering a multisystemic and interdisciplinary service to meet the children's physical, psychosocial and emotional needs shows heartening results and is worthy of further study.

Funding The authors would like to state a professional connection to Halliwell Homes Ltd. Parry worked for Halliwell Homes Ltd. from 2015 to 2019, Williams is a PhD researcher with funding from Halliwell Homes Ltd. Burbidge currently works for Halliwell Homes Ltd. No funding was available for this paper and the research was not conducted as a part of any paid employment or $\mathrm{PhD}$ related research.

\section{Declarations}

Conflict of interest The Restorative Parenting Recovery Programme is being piloted with the Social Enterprise Halliwell Homes Ltd. Halliwell Homes operate four residential treatment centres for children and young people who have experienced maltreatment. Dr Sarah Parry, practicing clinical psychologist, was working with Halliwell Homes when the Restorative Parenting Recovery Programme and accompanying measurement index were developed.

Open Access This article is licensed under a Creative Commons Attribution 4.0 International License, which permits use, sharing, adaptation, distribution and reproduction in any medium or format, as long as you give appropriate credit to the original author(s) and the source, provide a link to the Creative Commons licence, and indicate if changes were made. The images or other third party material in this article are included in the article's Creative Commons licence, unless indicated otherwise in a credit line to the material. If material is not included in the article's Creative Commons licence and your intended use is not permitted by statutory regulation or exceeds the permitted use, you will need to obtain permission directly from the copyright holder. To view a copy of this licence, visit http://creativecommons.org/licenses/by/4.0/.

\section{References}

Alvesson, M. (2003). Methodology for close-up studies: Struggling with closeness and closure. Higher Education, 46(2), 167-193. https://doi.org/10.1023/A:1024716513774

Bazalgette, L., Rahilly, T., \& Trevelyan, G. (2015). Achieving emotional wellbeing for looked after children: A whole system approach. NSPCC.

Berger, E. (2019). Multi-tiered approaches to trauma-informed care in schools: A systematic review. School Mental Health, 11(4), 650-664. https://doi.org/10.1007/s12310-019-09326-0

Berlin, L. J., Cassidy, J., \& Appleyard, K. (2008). The influence of eary attachments on other relationships. In J. Cassidy \& P. Shaver (Eds.), Handbook of attachment: Theory, research, and clinical applications. Guilford Publications.

Berridge, D. (2008). Educating difficult adolescents: effective education for children in public care or with emotional and behavioural difficulties. Jessica Kingsley. 
Bowlby, J. (1959). Child care and the growth of love. Pelican Books.

Braun, V., \& Clarke, V. (2006). Using thematic analysis in psychology. Qualitative Research in Psychology, 3(2), 77-101. https://doi.org/10.1191/1478088706qp063oa

Brännström, L., Vinnerljung, B., Forsman, H., \& Almquist, Y. B. (2017). Children placed in out-of-home care as midlife adults: Are they still disadvantaged or have they caught up with their peers? Child Maltreatment, 22(3), 205-214. https://doi.org/10.1177/1077559517701855

Bryson, S. A., Gauvin, E., Jamieson, A., Rathgeber, M., Faulkner-Gibson, L., Bell, S., \& Burke, S. (2017). What are effective strategies for implementing trauma-informed care in youth inpatient psychiatric and residential treatment settings? A realist systematic review. International Journal of Mental Health Systems, 11(1), 36-36. https://doi.org/10.1186/s13033-017-0137-3

Burbidge, C. E., Keenan, J., \& Parry, S. (2020). "I've made that little bit of difference to this child": Therapeutic parent's experiences of trials and triumphs in therapeutic children's homes. Journal of Workplace Behavioral Health, 35(4), 256-278. https://doi.org/10.1080/15555240.2020.1821205

Cannon, L. M., Coolidge, E. M., LeGierse, J., Moskowitz, Y., Buckley, C., Chapin, E., \& Kuzma, E. K. (2020). Trauma-informed education: Creating and pilot testing a nursing curriculum on traumainformed care. Nurse Education Today, 85, 104256. https://doi.org/10.1016/j.nedt.2019.104256

Cashmore, J., \& Shackel, R. (2014). Gender differences in the context and consequences of child sexual abuse. Current Issues in Criminal Justice, 26(1), 75-104. https://doi.org/10.1080/10345329.2014. 12036008

Clarke, A. (2011). Three therapeutic residential care models, the sanctuary model, positive peer culture and dyadic developmental psychotherapy and their application to the theory of congruence. Children Australia, 36(2), 81-87. https://doi.org/10.1375/jcas.36.2.81

Cohen, J. W. (1988). Statistical power analysis for the behavioral sciences (2nd ed.). L. Earlbaum Associates.

(House of) Commons EducationCommittee. (2016). Mental health and ell-being of looked after children: Fourth Report of Session 2015-2016. (HC 481) Retrieved from https://publications.parli ament.uk/pa/cm201516/cmselect/cmeduc/481/481.pdf

Day, A. G., Somers, C. L., Baroni, B. A., West, S. D., Sanders, L., \& Peterson, C. D. (2015). Evaluation of a trauma-informed school intervention with girls in a residential facility school: Student perceptions of school environment. Journal of Aggression, Maltreatment \& Trauma, 24(10), 1086-1105. https://doi.org/10.1080/10926771.2015.1079279

Dermody, A., Gardner, C., Davis, S., Lambert, S., Dermody, J., \& Fein, M. (2018). Resilience in the face of trauma: Implications for service delivery. Irish Probation Journal, 15, 161-178.

Dunn, W. (1999). The sensory profile. Psychological Corporation.

Department for Education (2017). Children looked after in England (including adoption), year ending 31 March 2017. Retrieved fromhttps://assets.publishing.service.gov.uk/government/uploads/system/ uploads/attachment_data/file/664995/SFR50_2017-Children_looked_after_in_England.pdf

Department for Education. (2018). Children looked after in England (including adoption), year ending 31 March 2018. Retrieved fromhttps://assets.publishing.service.gov.uk/government/uploads/system/uploads/attachment_data/file/757922/Children_looked_after_in_England_2018_Text_revised. pdf

Department for Education. (2019). Children looked after in England (including adoption), year ending 31 March 2019. Retrieved fromhttps://assets.publishing.service.gov.uk/government/uploads/system/uploads/attachment_data/file/850306/Children_looked_after_in_England_2019_Text.pdf

Felitti, V. J., Anda, R. F., Nordenberg, D., Williamson, D. F., Spitz, A. M., Edwards, V., \& Marks, J. S. (1998). Relationship of childhood abuse and household dysfunction to many of the leading causes of death in adults: The adverse childhood experiences (ACE) study. American Journal of Preventive Medicine, 14(4), 245-258. https://doi.org/10.1016/S0749-3797(98)00017-8

Furnivall, J., \& Grant, E. (2014, August 13). Trauma sensitive practice with children in care. Retrieved fromhttps://www.iriss.org.uk/resources/insights/trauma-sensitive-practice-children-care

Gaskill, R. L., \& Perry, B. D. (2011). Child sexual abuse, traumatic experiences, and their impact on the developing brain. In P. Goodyear-Brown (Ed.), Handbook of child sexual abuse: Identification, assessment, and treatment (pp. 29-47). Hoboken: Wiley.

Gaudion, K., Hall, A., Myerson, J., \& Pellicano, L. (2015). A designer's approach how can autistic adults with learning disabilities be involved in the design process? CoDesign CoDesign with People Living with Cognitive and Sensory Impairments, 11(1), 49-69. https://doi.org/10.1080/15710882. 2014.997829

Gilbert, R., Widom, C. S., Browne, K., Fergusson, D., Webb, E., \& Janson, S. (2009). Burden and consequences of child maltreatment in high-income countries. The Lancet, 373(9657), 68-81. https:// doi.org/10.1016/S0140-6736(08)61706-7 
Goodman, R. (1997). The strengths and difficulties questionnaire: A research note. Journal of Child Psychology and Psychiatry, 38(5), 581-586. https://doi.org/10.1111/j.1469-7610.1997.tb01545.x

Haggman-Laitila, A., Salokekkila, P., \& Karki, S. (2019). Young people's preparedness for adult life and coping after foster care: A systematic review of perceptions and experiences in the transition period. Child \& Youth Care Forum, 48(5), 633-661. https://doi.org/10.1007/s10566-019-09499-4

Halvorsen, T. (2014). Bridging the divide between education and social work in order to improve the prospects of looked after children. Scottish Journal of Residential Care, 13(1), 1-11.

Hernandez, P., Gangsei, D., \& Engstrom, D. (2007). Vicarious resilience: A new concept in work with those who survive trauma. Family Process, 46(2), 229-241. https://doi.org/10.1111/j.1545-5300.2007. 00206.x

Holden, M. J., Izzo, C., Nunno, M., Smith, E. G., Endres, T., Holden, J. C., \& Kuhn, F. (2010). Children and residential experiences: A comprehensive strategy for implementing a research-informed program model for residential care. Child Welfare, 89(2), 131-149. PMID: 20857884.

Horwitz, A. V., Widom, C. S., McLaughlin, J., \& White, H. R. (2001). The impact of childhood abuse and neglect on adult mental health: A prospective study. Journal of Health and Social Behavior, 42(2), 184-201.

Hummer, V. L., Dollard, N., Robst, J., \& Armstrong, M. I. (2010). Innovations in implementation of traumainformed care practices in youth residential treatment: A curriculum for organizational change. Child Welfare, 89(2), 79-95.

Joseph, S., Murphy, D., \& Regel, S. (2012). An affective-cognitive orocessing model of post-traumatic growth. Clinical Psychology and Psychotherapy, 19(4), 316-325. https://doi.org/10.1002/cpp.1798

Karver, M. S., Handelsman, J. B., Fields, S., \& Bickman, L. (2006). Meta-analysis of therapeutic relationship variables in youth and family therapy: The evidence for different relationship variables in the child and adolescent treatment outcome literature. Clinical Psychology Review, 26(1), 50-65. https://doi.org/ 10.1016/j.cpr.2005.09.001

Keselman, H. J., Cribbie, R. A., \& Holland, B. (2004). Pairwise multiple comparison test procedures: An update for clinical child and adolescent psycologists. Journal of Clinical Child and Adolescent Psychology, 33(3), 623-645. https://doi.org/10.1207/s15374424jccp3303_19

Macdonald, G., Millen, S., McCann, M., Roscoe, H., \& Ewart-Boyle, S. (2102). Therapeutic Approaches to Social Work in Residential Child Care Settings. Retrieved from London: https://www.scie.org.uk/publi cations/ataglance/ataglance58.asp

Madill, A., \& Gough, B. (2008). Qualitative research and its place in psychological science. Psychological Methods, 13(3), 254-271. https://doi.org/10.1037/a0013220

Malterud, K., Siersma, V. D., \& Guassora, A. D. (2016). Sample size in qualitative interview studies: Guided by information power. Qualitative Health Research, 26(13), 1753-1760. https://doi.org/10. $1177 / 1049732315617444$

McCann, J. B., James, A., Wilson, S., \& Dunn, G. (1996). Prevalence of psychiatric disorders in young people in the care system. BMJ, 313(7071), 1529-1530. https://doi.org/10.1136/bmj.313.7071.1529

McLeod, B. D. (2011). Relation of the alliance with outcomes in youth psychotherapy: A meta-analysis. Clinical Psychology Review, 31(4), 603-616. https://doi.org/10.1016/j.cpr.2011.02.001

Meltzer, M., Gatward, R., Corbin, T., Goodman, R., \& Ford, T. (2003). The mental health of young people looked after by local authorities in England. The Stationary Office.

Moore, T., McArthur, M., Death, T., Tilbury, C., \& Roche, S. (2018). Sticking with us through it all: The importance of trustworthy relationships for children and young people in residential care. Children and Youth Services Review, 84, 68-75. https://doi.org/10.1016/j.childyouth.2017.10.043

Morrison, R., \& Shepherd, M. (2015). Exploring factors contributing to the outcomes of looked after children. Communicare, 1(21), 2052-3297.

Mullan, C., McAlister, S., Rollock, F., \& Fitzsimons, L. (2007). "Care just changes your life": Factors impacting upon the mental health of children and young people with experiences of care in northern ireland. Child Care in Practice, 13(4), 417-434. https://doi.org/10.1080/13575270701488865

Nowell, L. S., Norris, J. M., White, D. E., \& Moules, N. J. (2017). Thematic analysis: Striving to meet the trustworthiness criteria. International Journal of Qualitative Methods. https://doi.org/10.1177/16094 06917733847

Parry, S. (2017). Effective self-care and resilience in clinical practice: Dealing with stress, compassion fatigue and burnout. Jessica Kingsley Publishers.

Parry, S., \& Weatherhead, S. (2014). A critical review of qualitative research into the experiences of young adults leaving foster care services. Journal of Children's Services, 9(4), 263-279. https://doi.org/10. 1108/JCS-04-2014-0022 
Parry, S. L., Simpson, J., \& Weatherhead, S. (2018). Changing relationships through interactions: Preliminary accounts of parent-child interactions after undertaking individual parent training. Child and Adolescent Social Work Journal, 35(6), 639-648. https://doi.org/10.1007/s10560-018-0547-3

Panlilio, C. C. (2019). Trauma-informed schools. Integrating child maltreatment prevention, detection, and intervention. Springer International Publishing. https://doi.org/10.1007/978-3-030-12811-1

Ribbens McCarthy, J., Hooper, C.-A., \& Gillies, V. (2013). Family troubles?: Exploring changes and challenges in the family lives of children and young people. The Policy Press.

Richardson, J., \& Lelliott, P. (2003). Mental health of looked after children. Advances in Psychiatric Treatment, 9(4), 249-251. https://doi.org/10.1192/apt.9.4.249

Roberts, L., Maxwell, N., Rees, P., Holland, S., \& Forbes, N. (2016). Improving well-being and outcomes for looked after children in Wales: A context sensitive review of interventions. Adoption \& Fostering, 40(4), 309-324. https://doi.org/10.1177/0308575916675563

Robinson, C., \& Brown, A. (2016). Considering sensory processing issues in residential child care settings for trauma affected children: The physical environment in children's residential homes. Scottish Journal of Residential Child Care, 15(1), 1478-1840.

Robinson, C., \& Philpot, T. (2016). Healing childhood trauma through restorative parenting: A model for supporting children and young people. Jessica Kingsley.

Roth-Yousey, L., Chu, Y. L., \& Reicks, M. (2012). A qualitative study to explore how parental expectations and rules influence beverage choices in early adolescence. Journal of Nutrition Education and Behavior, 44(6), 644-652. https://doi.org/10.1016/j.jneb.2011.07.005

Schofield, G., Biggart, L., Ward, E., \& Larsson, B. (2015). Looked after children and offending: An exploration of risk, resilience and the role of social cognition. Children and Youth Services Review, 51, 125-133. https://doi.org/10.1016/j.childyouth.2015.01.024

Seligman, M., \& Csikszentmihalyi, M. (2000). Positive psychology: An introduction. American Psychologist., 55(1), 5-14. https://doi.org/10.1037/0003-066X.55.1.5

Selwyn, J., Wood, M., \& Newman, T. (2017). Looked after children and young people in England: Developing measures of subjective well-being. Child Indicators Research, 10(2), 363-380. https:// doi.org/10.1007/s12187-016-9375-1

Shirk, S. R., \& Karver, M. (2003). Prediction of treatment outcome from relationship variables in child and adolescent therapy: A meta-analytic review. Journal of Consulting and Clinical Psychology, 71(3), 452-464. https://doi.org/10.1037/0022-006X.71.3.452

Shonkoff, J. P., Levitt, P., Bunge, S., Cameron, J. L., Duncan, G. J., Fisher, P. A., \& Nelson, C. A. (2015). Supportive Relationships and Active Skill-Building Strengthen the Foundations of Resilience: Working Paper No. 13. Retrieved from https://developingchild.harvard.edu/resources/suppo rtive-relationships-and-active-skill-building-strengthen-the-foundations-of-resilience/

Simkiss, D. E., Stallard, N., \& Thorogood, M. (2013). A systematic literature review of the risk factors associated with children entering public care. Child Care Health and Development, 39(5), 628642. https://doi.org/10.1111/cch.12010

Simmonds, J. (2016). Children in custody - 2015-2016 - an analysis of 12-18 year olds' perceptions of their experiences in secure training centres and young offenders institutions. HM Inspectorate of Prisons.

Snyder, C. R. (1994). The psychology of hope: You can get there from here. Free Press.

Sulimani-Aidan, Y., Melkman, E., \& Hellman, C. M. (2019). Nurturing the hope of youth in care: The contribution of mentoring. American Journal of Orthopsychiatry, 89(2), 134-143. https://doi.org/ 10.1037/ort0000320

Taku, K., Cann, A., Calhoun, L. G., \& Tedeschi, R. G. (2008). The factor structure of the posttraumatic growth inventory: A comparison of five models using confirmatory factor analysis. Journal of Traumatic Stress, 21(2), 158-164. https://doi.org/10.1002/jts.20305

Teyhan, A., Wijedasa, D., \& Macleod, J. (2018). Adult psychosocial outcomes of men and women who were looked-after or adopted as children: Prospective observational study. British Medical Journal Open, 8(2), e019095. https://doi.org/10.1136/bmjopen-2017-019095

Thomas, M., \& Isobel, S. (2019). 'A different kind of space': Mixed methods evaluation of facilitated reflective practice groups for nurses in an acute inpatient mental health unit. Archives of Psychiatric Nursing, 33(6), 154-159. https://doi.org/10.1016/j.apnu.2019.08.011

Treisman, K. (2017). Working with relational and developmental trauma in children and adolescents. Routledge.

Van der Kolk, B. A. (2003). The neurobiology of childhood trauma and abuse. Child and Adolescent Psychiatric Clinics of North America, 12(2), 293-317. https://doi.org/10.1016/S1056-4993(03) 00003-8 
Varese, F., Smeets, F., Kker, M., Lieverse, R., Lataster, T., Viechtbauer, W., \& Bentall, R. P. (2012). Childhood adversities increase the risk of psychosis: A meta-analysis of patient-control, prospective- and cross-sectional cohort studies. Schizophrenia Bulletin, 38(4), 661-671. https://doi.org/10. 1093/schbul/sbs050

Villodas, M. T., Litrownik, A. J., Newton, R. R., \& Davis, I. P. (2016). Long-term placement trajectories of children who were maltreated and entered the child welfare system at an early age: Consequences for physical and behavioral well-being. Journal of Pediatric Psychology, 41(1), 46-54. https://doi.org/10.1093/jpepsy/jsv031

Vogel, C. L. (2008). Classroom Design for Living and Learning with Autism. Autism Asperger's Digest. Retrieved from https://studylib.net/doc/7326575/classroom-design-for-living-and-learning-with-autism

Whittaker, J. K., Fernandez del Valle, J., \& Holmes, L. (2015). Therapeutic residential care for children and youth: developing evidence-based international practice. Jessica Kingsley Publishers.

Wilson, C., Pence, D. M., \& Conradi, L. (2013, November 04). Trauma-Informed Care. Encyclopedia of Social Work: Retrieved from . https://oxfordre.com/socialwork/view/https://doi.org/10.1093/acrefore/ 9780199975839.001.0001/acrefore-9780199975839-e-1063

Woodier, D. (2011). Building resilience in looked after young people: A moral values approach. British Journal of Guidance \& Counselling, 39(3), 259-282. https://doi.org/10.1080/03069885.2011.562638

Wooffitt, R., \& Widdicombe, S. (2006). Interaction in interviews. In P. Drew, G. Raymond, \& D. Weinerg (Eds.), Talk and interaction in social research methods (pp. 28-49). SAGE Publications Ltd.

Zatloukal, L., Žákovský, D., \& Tkadlčíková, L. (2020). 'Kids' skills' and 'Mission possible' innovations: Solution-Focused brief therapy models for working with children and adolescents revised and expanded. Australian and New Zealand Journal of Family Therapy, 41(1), 29-41. https://doi.org/10. 1002/anzf.1399

Publisher's Note Springer Nature remains neutral with regard to jurisdictional claims in published maps and institutional affiliations. 